\title{
Research on fuel consumption and emission of LNG bus with the different reduce emissions technology
}

\author{
Wang Changyuan Guo Yong \\ China Automotive Technology \& Research Center, Tianjin 300300 \\ wangchangyuan@catarc.ac.cn
}

\begin{abstract}
Keywords: LNG bus, fuel consumption, emission, acceleration performance.
\end{abstract}
Abstract. In this paper, the fuel consumption, vehicle emission and acceleration performance of two LNG bus were tested and compared by the heavy-duty chassis dynamometer and CVS emission test system. The reducing emission technology of two LNG bus respectively are the lean-burn with oxidation catalytic aftertreatment (DOC) technology and the equivalence ratio combustion with three way catalysts (TWC) technology. The results show that the emission and acceleration performance of the LNG bus using the equivalence ratio combustion with three way catalysts (TWC) technology was better than the LNG bus using the lean-burn with oxidation catalytic aftertreatment (DOC) technology. However, the fuel consumption of the LNG bus using equivalence ratio combustion with three way catalysts (TWC) technology was higher than the LNG bus using the lean-burn with oxidation catalytic aftertreatment (DOC) technology.

\section{Introduction}

Buses as the main heavy-duty vehicle run in the city. They often run in densely occupied area. the running time and millage of buses are very long. Therefore, the major cities on the bus emissions requirements are very strict. In 2008, Beijing began to implement the GUO IV emission standards for public transportation and began to implement the GUO V emission standards in 2009.

Natural gas is the world's third largest natural energy, second only to coal and oil. The main component of natural gas is methane, which generates carbon dioxide and water after burning. The pollutants emitted by natural gas combustion are less[1]. Natural gas as alternative fuel in our country has been applied to the bus, including CNG bus and LNG bus.

At present, the national heavy duty vehicle emission standard GB17691-2005 requires that the heavy duty vehicle's emission test is based on the engine bench test. the gas pollutants of natural gas engine are tested by the engine test bench and base on the European Transient Cycle(ETC). At present, China's demand for natural gas engine must meet the fifth phase of the national emission standards. In order to meet the requirements of GUO V emission standards, the two technologies of reducing emission is used on the natural gas engine, including engine using lean combustion and DOC technology and engine using fuel air equivalence ratio combustion and TWC technology.

Based on engine bench test method, many tests and researches have been done on the two kinds of natural gas engine emissions at home and abroad[2,3]. The emission of natural gas vehicle is tested by PEMS on the actual road[4, 5]. However, the study paper is very small about the emission of natural gas vehicle tested by the heavy-duty chassis dynamometer.

In this paper, based on the heavy-duty chassis dynomometer and CVS emission test system, the fuel consumption, emission and acceleration performance of two GUO V natural gas buses are tested and compared with a GUO V diesel bus. Two buses were using the lean combustion and DOC technology and fuel air equivalence ratio combustion and TWC Technology.

\section{Test equipment}

The heavy-duty test bench is composed of three systems, including dynamometer system, revolving drum system and CVS emission test system. The structure diagram can be shown in the figure 1 . 
In this experiment, the heavy-duty chassis dynamometer named MAHA made in German is used to test emission. There are four revolving drum. The diameter of revolving drum is 72 inches. The distance of revolving drum can be adjusted. The scan of adjustment is $3.2 \mathrm{~m}-8 \mathrm{~m}$. The power of former drum is $250 \mathrm{kw}$ and the power of back drum is $549 \mathrm{kw}$. The highest vehicle weight that can be simulated is $35 \mathrm{t}$. It can be satisfy requirement for testing all kinds of driving mode vehicle, for instant, $4 \mathrm{X} 4,6 \mathrm{X} 6,8 \mathrm{X} 8$ and so on. There are very sensitive control system and electronic inertia analog device on the chassis dynamometer. So it can for dynamic testing.

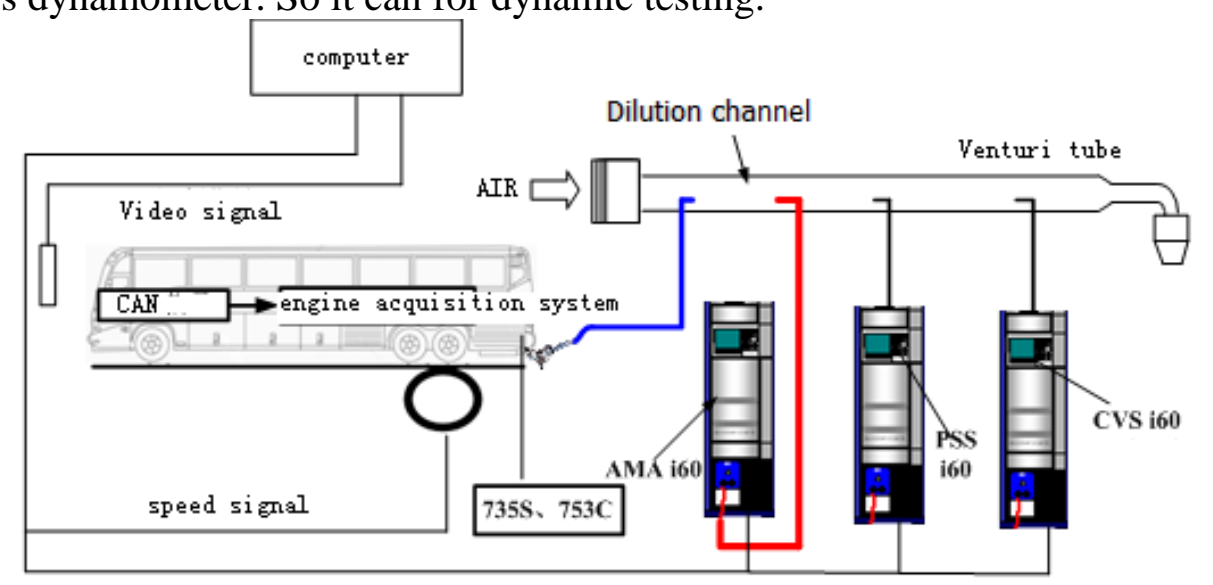

Fig.1 the heavy-duty chassis dynamometer test system

\section{Test method}

The table 1 shows the basic information of there buses. The bus 1 and bus 2 is the liquefied natural gas(LNG) bus and the bus 3 is diesel bus. The body long and gross vehicle weight $(\mathrm{GVW})$ of three buses are $12 \mathrm{~m}$ and $18 \mathrm{t}$. The rated power of engine is $200 \mathrm{~kW}$. The transmission is $6 \mathrm{MT}$. The reducing emission technology of the bus 1 is the lean combustion and DOC. The reducing emission technology of the bus 2 is the fuel air equivalence ratio combustion and TWC.

Tab. 1 the basic parameters of vehicle

\begin{tabular}{|c|c|c|c|}
\hline Items & Bus 1 & Bus 2 & Bus 3 \\
\hline GVW[kg] & 17800 & 17800 & 17800 \\
\hline Long*width*hight[m] & $12 \times 2.5 \times 3.3$ & $12 \times 2.5 \times 3.2$ & $12 \times 2.5 \times 3.2$ \\
\hline Gears & 6 & 6 & 6 \\
\hline Fuel & LNG & LNG & \\
\hline Cylinder number & 6 & 6 & 6 \\
\hline Compression ratio & $11.5: 1$ & $11.5: 1$ & $17.2: 1$ \\
\hline Displacement[ L] & 10.338 & 8.9 & 8.424 \\
\hline Rated power[kW/rpm] & $236 / 2100$ & $209 / 2000$ & SCR \\
\hline Aftertreament & DOC & TWC & GUO 5 \\
\hline Emission standard & GUO 5 & GUO 5 & \\
\hline
\end{tabular}

The test based on GB/T27840-2011 standard. The resistance load of the vehicle is provided by the chassis dynomometer. The vehicle load is set to $100 \%$. The emission of bus is tested by CVS. The test cycle is China typical city bus cycle(CCBC), as can be seen in the figure 2 . The CCBC cycle is developed based on the data of 3 urban buses running in Beijing, Shanghai and Guangzhou. The $\mathrm{CCBC}$ cycle is more representative of China's traffic and road conditions[6]. 


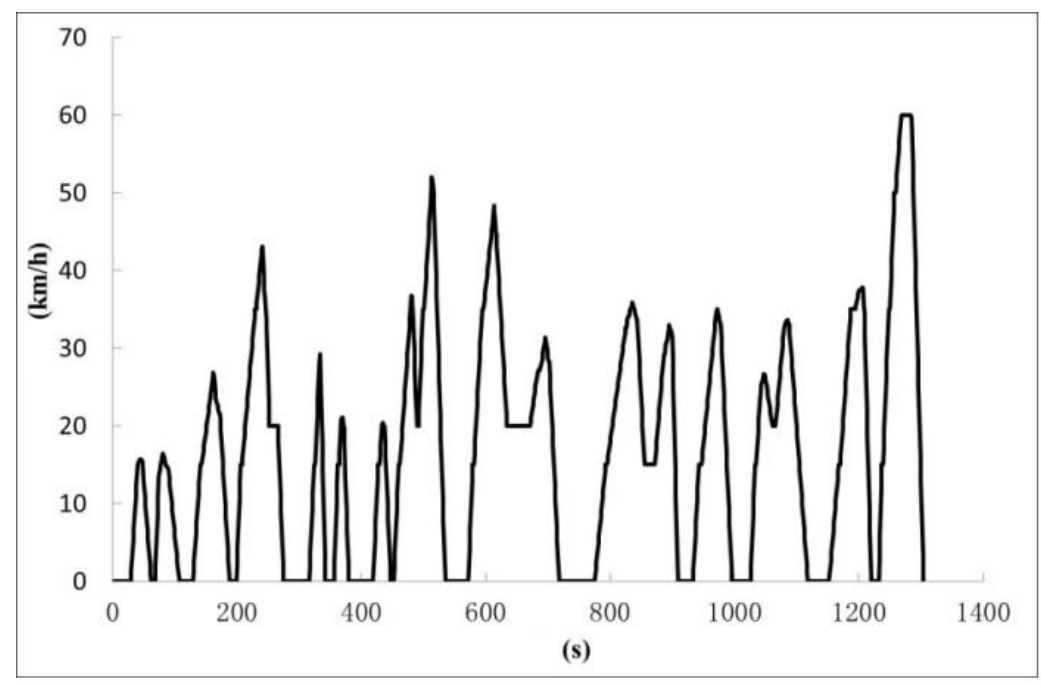

Fig.2 CCBC cycle

\section{Result analysis of fuel consumption}

In the vehicle test process, the vehicle of the test cycle repetition accuracy have great influence on the measurement results. If the cycle is difficult to reproduce, The comparison of the test results is less convincing. The figure 3 shows the correlation contrast results of actual speed and CCBC speed of three buses. The results can be seen from the figure, the actual speed of the test vehicle and the setting speed of the test cycle are linear correlation. The proportion coefficient of fitting straight line is more than 0.99 , and close 1 . The correlation coefficient is near 0.99 . It can prove that the three buses basically resembles the CCBC cycle.

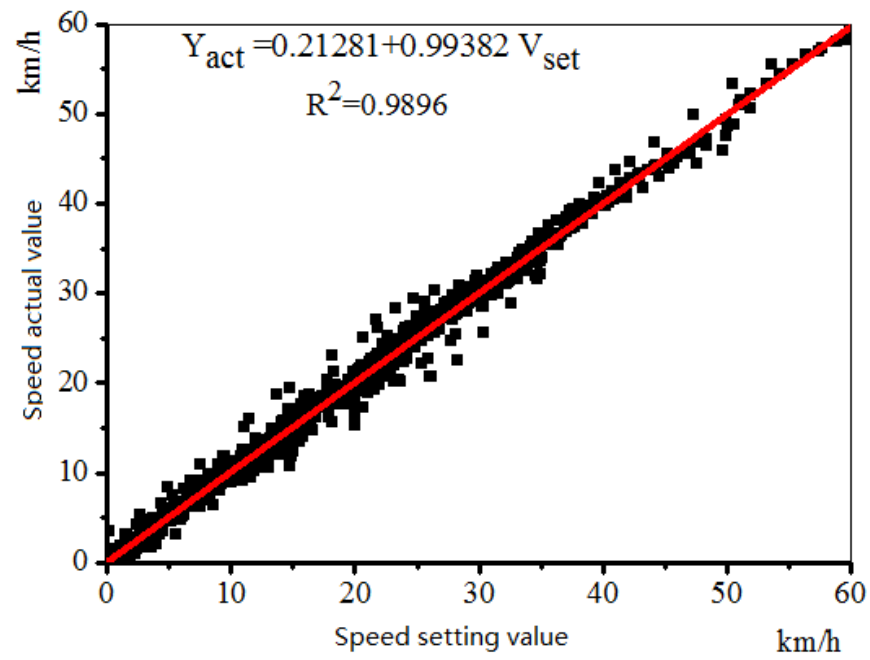

Fig. 3 Correlation between actual speed and set speed

The measurement method of diesel and natural gas fuel consumption is recommended by the national standards GB/T27840-2011 and GB/T29125-2012. The calculation method of natural gas fuel consumption converted to liquid fuel consumption is provided in the GB/T29125-2012, the following formula can be used:

$$
F C_{N G-1}=\frac{Q_{N G}}{Q_{l} \times d_{l}} \times F C_{N G} \quad 1
$$

$\mathrm{F}_{\mathrm{CNG}-1}$ : fuel consumption of natural gas vehicles converted to liquid fuel vehicles [L/100km].

$\mathrm{FC}_{\mathrm{NG}}$ : fuel consumption of natural gas vehicle $\left(15^{\circ} \mathrm{C} 、 101.325 \mathrm{kPa}\right)[\mathrm{m} 3 / 100 \mathrm{~km}]$.

$\mathrm{Q}_{\mathrm{l}}$ : Low calorific value of liquid fuel[MJ/kg], diesel=42.652 MJ $/ \mathrm{kg}$.

$\mathrm{d}_{1}$ : Liquid fuel density $\left(15^{\circ} \mathrm{C} 、 101.325 \mathrm{kPa}\right)[\mathrm{kg} / \mathrm{L}]$, diesel $=0.83 \mathrm{~kg} / \mathrm{L}$

$\mathrm{Q}_{\mathrm{NG}}$ : Low calorific value of natural gas is $32.74 \mathrm{MJ} / \mathrm{m}^{3}\left(15^{\circ} \mathrm{C} 、 101.325 \mathrm{kPa}\right)\left[\mathrm{MJ} / \mathrm{m}^{3}\right]$. 
The density of natural gas is $0.654 \mathrm{~kg} / \mathrm{m}^{3}\left(15^{\circ} \mathrm{C} 、 101.325 \mathrm{kPa}\right)$. The figure 4 shows the comparison results of the fuel consumption of three buses. In the figure, the LNG consumption of LNG bus and the diesel consumption converted by the formula 1 are given respectively. The results can be seen from the figure 4 , the fuel consumption of the bus 2 with fuel air equivalence ratio combustion and TWC technology is $16.8 \%$ higher than the bus 1 with the lean combustion and DOC technology. The diesel consumption converted by the formula 1 of the bus 1 and bus 2 are $46.1 \%$ and $70.6 \%$ higher than the diesel bus 3

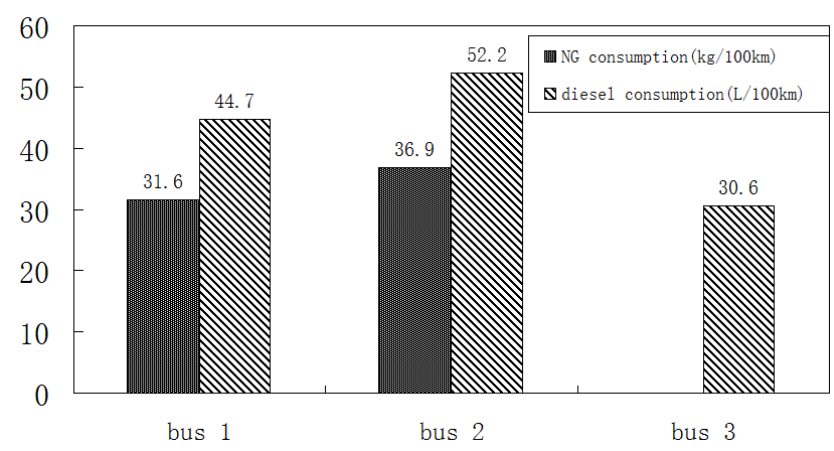

Fig.4 the comparison results of the fuel consumption of three buses

\section{Result analysis of gas emission}

The table 2 shows emission factor (slash left) and specific emission (slash right) results of three buses. The results can be seen from table 2, the $\mathrm{CO}$ emission of natural gas bus with DOC or TWC is smaller than the diesel bus. Because the diesel bus don't have the reducing $\mathrm{CO}$ aftertreatment. For $\mathrm{HC}$ emission, the main components of $\mathrm{HC}$ pollutants of natural gas bus is $\mathrm{CH}_{4}$. The $\mathrm{CH}_{4}$ emission of bus 1 is 15 times the bus 2 . The NOx emission of bus 1 is highest because that don't have the reducing NOx aftertreatment.

Tab.2 the comparison results of gas emission of three buses $(\mathrm{g} / \mathrm{km}$ and $\mathrm{g} / \mathrm{kWh})$

\begin{tabular}{|c|c|c|c|}
\hline emission & Bus 1 & Bus 2 & Bus 3 \\
\hline CO & $0.23 / 0.16$ & $0.48 / 0.31$ & $1.03 / 0.51$ \\
\hline NMHC & $<0.001$ & $<0.001$ & $0.065 / 0.032$ \\
\hline CH4 & $6.98 / 5.02$ & $0.46 / 0.31$ & $0.0031 / 0.0015$ \\
\hline NOX & $23.44 / 16.82$ & $2.34 / 1.54$ & $12.58 / 6.16$ \\
\hline
\end{tabular}

The figure 5 shows the average exhaust temperature of three buses. The exhaust temperature of natural gas bus is higher because of using premixed combustion mode. The exhaust temperature of bus 2 is highest because of using fuel air equivalence ratio combustion. The exhaust temperature influence aftertreatment conversion efficiency. Only the exhaust temperature reached $200^{\circ} \mathrm{C}$, the SCR aftertreatment can work normally. The NOx emission of bus 3 is highest because the exhaust temperature of bus 3 don't reach $200^{\circ} \mathrm{C}$. The DOC and TWC reach highest work efficiency when the exhaust temperature reach $350^{\circ} \mathrm{C}$. So the emission of bus 2 is smallest. 


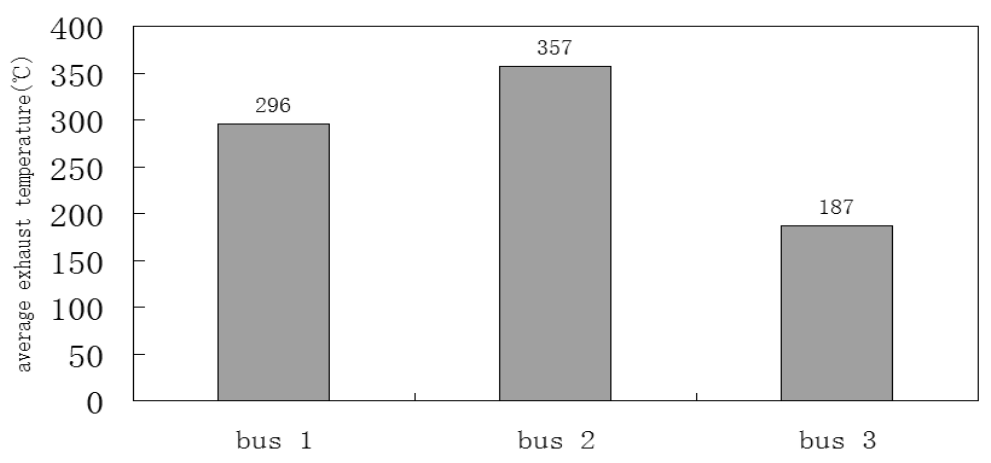

Fig.5 the comparison results of the PM emission of three buses

\section{Result analysis of PM engnie}

The figure 6 shows the comparison results of the PM results of three buses. The results can be seen from figure 6, the PM emission of natural gas bus is very small and can be neglected.

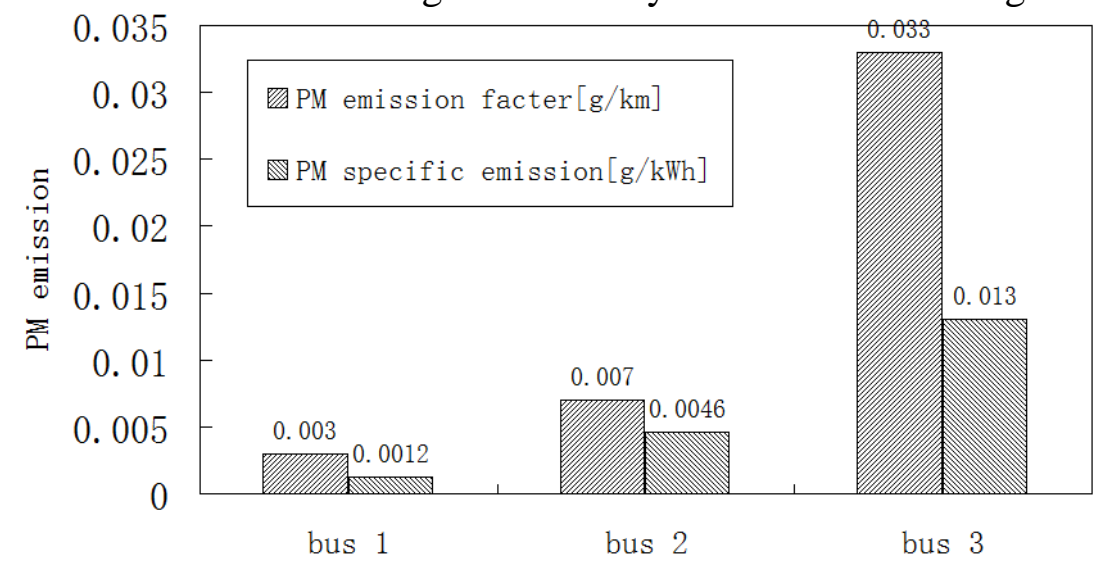

Fig.6 the average exhaust temperature of three buses

\section{Summary}

The research work of this thesis is summarized as follows:

(1) For fuel consumption, the use of TWC technology for fuel consumption and LNG bus consumption is higher than that of the LNG bus with a lean burn and DOC technology. The consumption of natural gas in LNG bus is more than that of the diesel fuel consumption;

(2) The NOx emissions of DOC and $\mathrm{CH} 4$ are the highest, and the emission of TWC is the best, which is based on the effect of exhaust gas temperature;

(3) The PM emissions of LNG buses are few, and the basic negligible;

\section{References}

[1] YAO Bao-feng, LI Guo-xiu. Study on Influencing Factors of Cycle-to-cycle Combustion Variations in a Lean Burn Natural Gas Engine[J]. Chinese Internal Combustion Engine Engineering, 2007.

[2] Ma Fanhua, Wang Junjun, Chen Wei, Wu Xiao, Li Yong, Wang Yu. Emission Characteristic of Turbocharged Lean Burn CNG Engine[J]. Chinese Internal Combustion Eng ine Eng ineering, 2008, 29(2): 10-14.

[3] EINEWAl. L P, TUNEST L P, JOHANSSON B. Lean burn natural gas operation vs. Stoichiometric operation with EGR and a three way catalyst[C], SAE 2005 world Congress, April 11-14, 2005, Detroit, Michigan, USA. Warrendale: SAE International, 2005. 
[4] L. Pelkmans, D. De Keukeleere \& G. Lenaers. Emissions And Fuel Consumption Of Natural Gas Powered City Buses Versus Diesel Buses In Real- City Traffic[C]. Seventh International Conference on Urban Transport and the Environment in the 21st Century, 2001.

[5] Guo Jiadong, Ge Yunshan, Tan Jianwei, Zhang Xuemin, Yu Linxiao, Fu Mingliang. A Research on the Real World Emission Characteristics of State-V Buses[J]. Automotive Engineering, 2015, 37(1): 121-124.

[6] GB/T 19754-2005 Test methods for energy consumption of heavy-duty hybrid electric vehicle

[7] Masaki Okad. Development of CNG Direct Injection Diesel-Cycle Engine[R]. NGV2004 